\title{
Ultraviolet A exposure induces reversible disruption of gap junction intercellular communication in lens epithelial cells
}

\author{
DAYANG WU, JIANGYUE ZHAO, DI WU and JINSONG ZHANG \\ Department of Ophthalmology, The Fourth Affiliated Hospital of China Medical University, Eye Hospital of China \\ Medical University, Key Lens Research Laboratory of Liaoning Province, Shenyang 110005, P.R. China
}

Received January 27, 2011; Accepted March 16, 2011

DOI: 10.3892/ijmm.2011.665

\begin{abstract}
Gap junction intercellular communication (GJIC) is essential for the proper function of many organs including the lens. Disruption of GJIC can cause lens metabolic disorder and can induce cataracts. The purpose of this study was to investigate the signal transduction pathways involved in GJIC disruption following ultraviolet A (UVA) exposure in lens epithelial cells. Following exposure of human lens epithelial cells to UVA, connexin 43 (Cx43), the main component of gap junctions, was down-regulated at both the mRNA and protein levels. Furthermore, we observed that UVA exposure can increase protein kinase $\mathrm{C}$ activity and stimulate reactive oxygen species generation and lipid peroxidation. Using scrape load dye transfer technique, we found that the GJIC is compromised by UVA exposure. In addition, we demonstrated that UVA-induced modulation of GJIC was associated with p38 mitogen-activated protein kinase activation. More importantly, at non-lethal doses $\left(10 \mathrm{~J} / \mathrm{cm}^{2}\right)$, the UVA-induced GJIC disruption and the consequent alterations were reversible. Collectively, our data revealed a new signaling pathway in GJIC disruption following UVA exposure, suggesting that UVA-compromised gap junction activity may sensitize human lens to photoaging and cataract formation.
\end{abstract}

\section{Introduction}

Cataract is a clouding of the lens in the eye that affects vision and is the leading cause of blindness in the world. Cataract develops for a variety of reasons, such as long-term exposure to ultraviolet (UV) light, exposure to radiation, diabetes, alcohol, smoking, diet, and steroid use (1-3). Among these causative factors for cataract formation, UV-irradiation has received considerable attention as the eye needs light to

Correspondence to: Dr Jinsong Zhang, Department of Ophthalmology, The Fourth Affiliated Hospital of China Medical University, Eye Hospital of China Medical University, Key Lens Research Laboratory of Liaoning Province, 11 Xinhua Road, Shenyang 110005, P.R. China

E-mail: cmu4h-zjs@126.com

Key words: gap junction intercellular communication, ultraviolet A, lens epithelial cells, connexin 43, p38 provide vision and the lens receives UV-radiation. UV from natural sunlight is a form of non-ionizing radiation, within the wavelength range of $200-400 \mathrm{~nm}$. According to biological functions, UV rays can be divided into UVC (200-280 nm), UVB (280-320 $\mathrm{nm}$ ) and UVA (320-400 $\mathrm{nm})$. In general, UVB rays are primarily absorbed by the cornea, while the majority of UVA rays are absorbed by the lens. A number of studies have shown that UV-radiation modulated reactive oxygen species (ROS) results in degradation, cross-linking, and aggregation of lens proteins and DNA damage, which is regarded as an important factor in cataractogenesis (4-6). However, the precise mechanism of UV-radiation-induced cataract formation is unclear.

Intercellular communication through gap junctions plays a critical role in the maintenance of tissue homeostasis $(7,8)$. Gap junctions are intercellular channels that allow the direct exchange of low-molecular-weight ( $\leq 1000 \mathrm{Da})$ solutes such as ions $\mathrm{Na}^{+}, \mathrm{K}^{+}, \mathrm{H}^{+}$and cyclic nucleotides $(9,10)$. By mediating the regulated intercellular diffusion of substances, gap junction intercellular communication (GJIC) plays an important role in the regulation of proliferation and differentiation, which is essential for the proper function of many organs, including the lens. Gap junctions are formed by a family of closely related proteins termed connexin (Cx). Six $\mathrm{Cx}$ subunits form a hemichannel. Each $\mathrm{Cx}$ has four transmembrane domains, one intracellular loop and two extracellular loops. The intra-cellular domains contain the $\mathrm{COOH}$ and $\mathrm{NH}_{2}$ termini that control channel activities and determine its specificity $(11,12)$. Based on the species and molecular weight, cDNA clone-derived Cx43, Cx46, Cx50, Cx56, Cx45.6, Cx44 and Cx49 were found to be expressed in the lens of human and vertebrate animals (13). Eckert et al developed a simple dye transfer method that can quantify intercellular dye diffusion through gap junctions in the mammalian lens to determine GJIC activity (14). They introduced two fixable fluorescent dyes, Lucifer yellow and rhodamine-dextran, into lens fiber cells via mechanical damage induced by removing the lens capsule. The lenses were incubated in the dye solutions for several minutes and subsequently examined by confocal microscopy. The high molecular weight dye rhodaminedextran is impermeable through gap junctions and was used to identify the cells that have initially been loaded with tracer. The low molecular weight Lucifer yellow dye is gap junction permeable and acts as a tracer for diffusion through 
the gap junction channels. Using this method, they were able to determine a value for the absolute permeability of the gap junctions that connect the fiber cells in the lens cortex.

A number of studies have been performed to explore the possible mechanisms by which disruption of GJIC can induce cataract formation. Baruch et al have found that dysfunction of GJIC caused by $\mathrm{Cx}$ damage will lead to increased $\mathrm{Ca}^{2+}$ influx and will result in ion metabolic disorders. Accumulation of calcium in the lens subsequently activates calcium-dependent cysteine proteases that result in crystal protein aggregation and lens opacification (15). A previous study has also shown that GJIC activity can be inhibited under high glucose conditions in lens epithelial cells, suggesting a role for GJIC in permeable edema and ion metabolic disorders in the diabetic lens (16). Disruption of GJIC has been reported to promote lens epithelial cell apoptosis, which is a common pathological finding in many types of cataracts and important in the pathogenesis of cataract (17).

Phosphorylation of $\mathrm{Cx} 43$ can rapidly adjust the channel's open and closed status, and change the number of active channels by affecting Cx43 synthesis, transport, aggregation, disaggregation and degradation, thus ultimately regulating the function of the gap junction. UV and several kinases, include protein kinase $\mathrm{C}$ (PKC), mitogen-activated protein kinase (MAPK) and casein kinase (CK) I and II have been found to regulate $\mathrm{Cx} 43$ phosphorylation, thus affecting the function of gap junction channels (18-20). Therefore, research on the UVA-induced phosphorylation of $\mathrm{Cx} 43$ and its relationship to the lens gap junction, as well as the effect of non-lethal UVA on the lens epithelial cells is of great significance. In this study, we aimed to investigate the signal transduction pathways involve in GJIC disruption following UVA exposure in lens epithelial cells. We found that UV disrupted GJIC activity through down-regulation of $\mathrm{Cx} 43$ expression, and this disruption was reversible in a p38-dependent manner.

\section{Materials and methods}

Cell culture. The human lens epithelial cell line SRA01/04 was obtained from the American Type Culture Collection (ATCC, Manassas, VA, USA). Cells were cultured in Dulbecco's modified Eagle's medium (DMEM, Gibco, Grand Island, NY, USA) supplemented with $10 \%$ heat-inactivated fetal bovine serum at $37^{\circ} \mathrm{C}$ in a humidified atmosphere of $5 \% \mathrm{CO}_{2}$ and $95 \%$ air.

UVA-irradiation and cell viability assay. Confluent SRA01/04 cells were irradiated with UVA $365 \mathrm{~nm}$ at a dose of $10 \mathrm{~J} / \mathrm{cm}^{2}$ for $2 \mathrm{~h}$. Cells were irradiated in PBS to avoid secondary toxicity due to culture medium modifications. After removal of PBS and addition of culture medium, irradiated cells were incubated at $37^{\circ} \mathrm{C}$ in $5 \% \mathrm{CO}_{2}$ for various times. Unirradiated PBS-treated SRA01/04 cells were used as control.

Cell viability after UVA-irradiation was measured by a cell counting kit (CCK-8) assay (Beyotime Institute of Biotechnology, Haimen, China). SRA01/04 cells were suspended at a final concentration of 2000 cells/well and cultured in 96-well flatbottomed microplates. After exposure to UVA for various doses, CCK-8 $(10 \mu \mathrm{l})$ was added to each well and incubated for $1 \mathrm{~h}$ at $37^{\circ} \mathrm{C}$. Viable cells were counted by absorbance measurements at $450 \mathrm{~nm}$ (OD 450) using a microplate reader.
The OD 450 value was proportionally and inversely correlated to the degree of cell apoptosis. All experiments were performed in triplicate and repeated at least three times.

RNA isolation and real-time RT-PCR. Total-RNA was isolated from treated and control cells at designated time points using the RNAsimple total-RNA kit (Tiangen Biotechnology Co., Ltd., Beijing, China) according to the manufacturer's instruction. For reverse transcription, $2 \mu \mathrm{g}$ of total-RNA was used to make $20 \mu \mathrm{l}$ cDNA using the Superscript first strand synthesis kit system according to the manufacturer's protocol (Tiangen). Quantitative real-time PCR was carried out in $20 \mu \mathrm{l}$ of reaction mixture containing $10 \mu \mathrm{l}$ of $2 \mathrm{X}$ SYBR-Green Master mix (Tiangen), $0.5 \mu \mathrm{M}$ of forward and reverse primers, and $1.5 \mu \mathrm{l}$ template cDNA on a Exicycler 96 real-time PCR system (Bioneer, Daejeon, Korea) under the following conditions: $95^{\circ} \mathrm{C}$ for $10 \mathrm{~min}$, followed by 35 cycles of $95^{\circ} \mathrm{C}$ for $10 \mathrm{sec}, 58^{\circ} \mathrm{C}$ for $20 \mathrm{sec}$ and $68^{\circ} \mathrm{C}$ for $40 \mathrm{sec}$. The primers for Cx43 were: 5'-TCTGAGTGCCTGAACTTGC-3' (sense) and 5'-ACTGACAGCCACACCTTCC-3' (antisense). Constitutively expressed $\beta$-actin mRNA was simultaneously assayed as an internal standard for sample normalization. All experiments were performed in triplicate and repeated at least three times. The expression of the $\mathrm{Cx} 43$ mRNA was calculated using the $2^{-\triangle \Delta C T}$ method as previously described (21).

Western blotting. Cells were lysed by sonication in a buffer containing $15 \mathrm{mM}$ Tris- $\mathrm{HCl}$ (pH 6.8), $10 \%$ glycerol, $2 \%$ SDS, and $6 \% \beta$-mercaptoethanol. Protein concentration was determined by the Bradford method. After incubation at $95^{\circ} \mathrm{C}$ for $10 \mathrm{~min}$, equal volumes of protein extracts were separated by $10 \%$ SDS-PAGE. The proteins were then transferred to an Immobilon ${ }^{\mathrm{TM}}$ PVDF membrane using a Western blotting apparatus. Membranes were blocked with $5 \%$ w/v non-fat dry milk and $0.1 \% \mathrm{v} / \mathrm{v}$ Tween-20 in PBS, and incubated with antiCx43 (1:1000, Santa Cruz Biotechnology, Santa Cruz, CA, USA), anti-phospho-p38 (1:1000, Abcam, Cambridge, MA, USA), anti-p38 (1:1000, Abcam) or anti-GAPDH antibodies (1:5000, Abcam) overnight at $4^{\circ} \mathrm{C}$. Signals were visualized with a Phototope-HRP Western blotting detection kit (Cell Signaling Technology, Danvers, MA, USA).

PKC activity assay. After UVA-irradiation at a dose of $10 \mathrm{~J} / \mathrm{cm}^{2}$, SRA01/04 cells were incubated for different time points at $37^{\circ} \mathrm{C}$. PKC activity assay was performed using a PKC enzyme assay system (Genmed, Shanghai, China) according to the manufacturer's instruction. Results were analyzed with NanoDrop 2000 (Thermo Fisher Scientific Inc., Waltham, MA, USA) at $340 \mathrm{~nm}$ $0 \mathrm{~min}-340 \mathrm{~nm} 5 \mathrm{~min}$, and data were normalized to the sample protein concentration.

Measurement of reactive oxygen species (ROS) and lipid peroxidation. After UVA-irradiation, cells were incubated at $37^{\circ} \mathrm{C}, 5 \% \mathrm{CO}_{2}$ for various time points for repair. Cells were then incubated with the DCFH-DA probe (Beyotime) for $20 \mathrm{~min}$. ROS was measured by flow cytometry using the ROS detection kit (Beyotime). Lipid peroxidation due to UVA-irradiation was measured as previously described (20). Briefly, SRA01/04 cells were plated in $60-\mathrm{mm}$ petri dishes, $10^{6}$ cells/dish, and incubated at $37^{\circ} \mathrm{C}$ overnight. After UVA irradiation with $10 \mathrm{~J} / \mathrm{cm}^{2}$, cells 


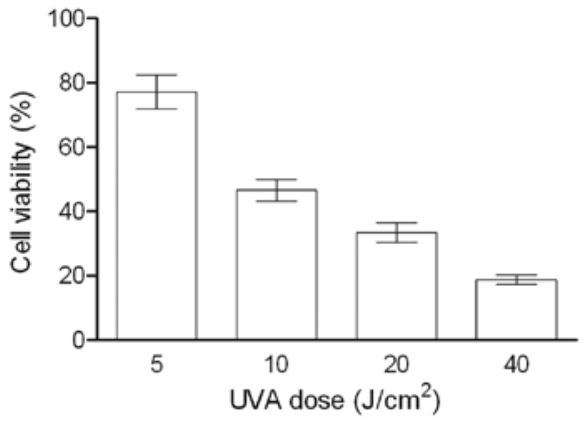

Figure 1. Cell viability after UVA $(365 \mathrm{~nm})$ irradiation of lens epithelial cells. SRA01/04 cells were irradiated with UVA at doses of 5, 10, 20 and $40 \mathrm{~J} / \mathrm{cm}^{2}$. Cell viability was measured by the CCK- 8 assay. Absorbance was read at $450 \mathrm{~nm}$. The means and standard deviation (error bar) from three experiments are depicted.

were incubated for various time points. Supernatants $(200 \mu \mathrm{l})$ were collected and malondialdehyde (MDA) was measured with the thiobarbituric acid-reactive substances (TBARS) using the MDA assay kit (Beyotime). Data were normalized to the protein content of the same cells measured using the BCA kit (Beyotime). Data are expressed as the mean \pm SD from 3 petri-dishes.

Scrape load dye transfer technique (SLDT). SLDT was used to assess GJIC activity as described previously $(22,23)$. Briefly, after UVA-irradiation, the cells were washed three times with PBS, and $1.5 \mathrm{ml}$ of PBS containing $0.05 \%$ Lucifer yellow fluorescent dye and $0.05 \%$ rhodamine-dextran was added. Several scrapes (cuts) were made on the monolayer using a surgical scalpel. The cells were incubated for $3 \mathrm{~min}$ at $37^{\circ} \mathrm{C}$ and then rinsed three times with PBS. The cells were then fixed with $4 \%$ paraformaldehyde in PBS and photographed with a digital camera attached to a fluorescence microscope (Motic Electric Group Co., Ltd., Xiamen, China).

Statistical analysis. All data are expressed as means \pm SD and raw data were analyzed by the unpaired Student's t-test using the SPSS 13.0 software (SPSS Inc., Chicago, IL, USA). A P-value $<0.05$ was considered to be statistically significant.

\section{Results}

Lens epithelial cell line SRA01/04 sensitivity to UVA-irradiation. Confluent cells in 96-well plates were irradiated with UVA at doses ranging from $5-40 \mathrm{~J} / \mathrm{cm}^{2}$. Cell viability was measured by the CCK- 8 assay and the values are shown in Fig. 1. At a dose of $5 \mathrm{~J} / \mathrm{cm}^{2}$, cell viability was $\sim 80 \%$. Cell viability remarkably decreased after an increase of the UVA dose to $40 \mathrm{~J} / \mathrm{cm}^{2}$. Cell viability was $46.4 \%$ at $10 \mathrm{~J} / \mathrm{cm}^{2}$ and this UVA dose was used in subsequent experiments.

Cx43 expression in UVA-irradiated lens epithelial cells. $\mathrm{Cx} 43$ mRNA levels were determined by means of real-time RT-PCR. When measured immediately after UVA-irradiation, Cx43 mRNA levels were significantly decreased compared to control cells (Fig. 2A). Cx43 mRNA levels were slightly increased $1 \mathrm{~h}$ after irradiation and remained higher 2-8 h thereafter. $\mathrm{Cx} 43$ mRNA levels returned to normal levels (those of control cells)
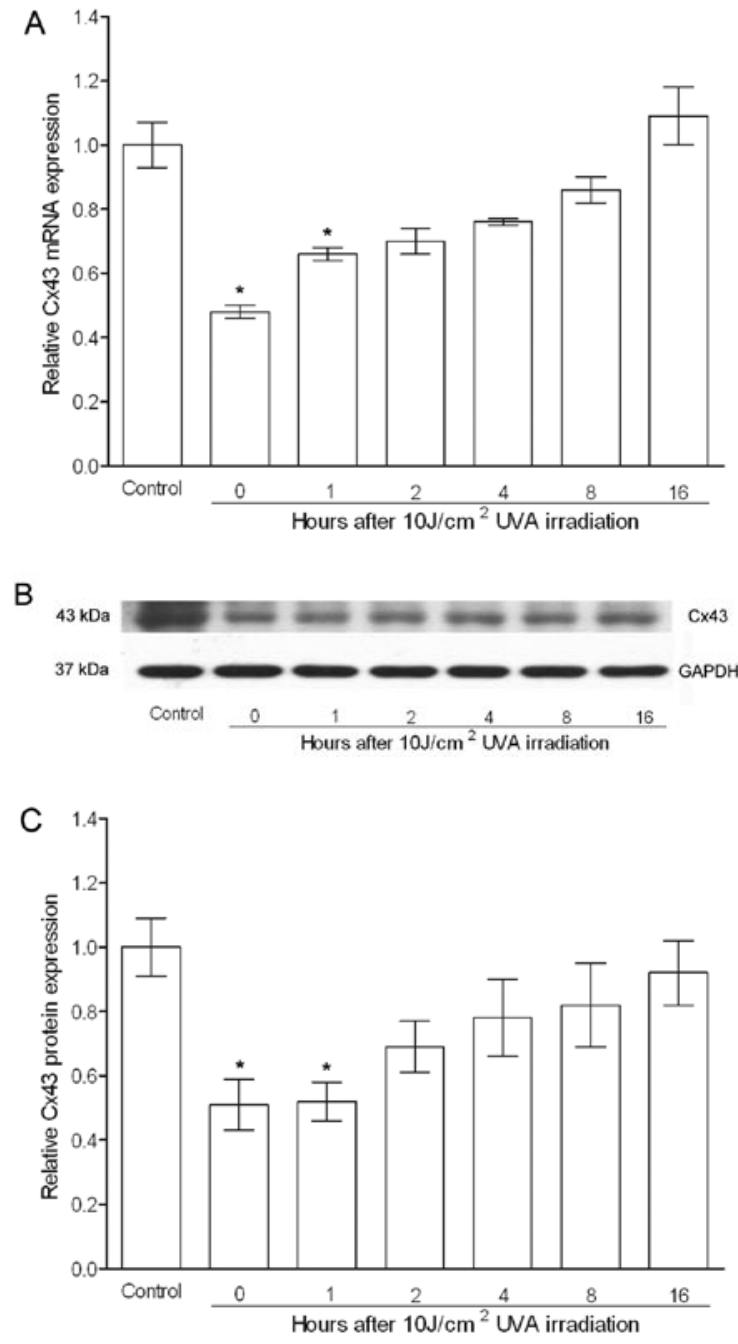

Figure 2. Cx43 expression in UVA irradiated lens epithelial cells. Cells were exposed to $10 \mathrm{~J} / \mathrm{cm}^{2}$ of UVA, and incubated for up to $16 \mathrm{~h}$. (A) Cx43 mRNA levels were determined by real-time RT-PCR. Cx43 mRNA was significantly decreased after UVA-irradiation, but slightly increased $1 \mathrm{~h}$ after irradiation and remained higher thereafter. (B) Western blot analysis showed the same pattern of change in $\mathrm{Cx} 43$ protein levels after UVA-irradiation. Equivalent loading of the cell lysates was determined by anti-GAPDH immunoblotting. (C) Quantitative expression level of $\mathrm{Cx} 43$ protein was analyzed by measuring band density on the gel image. The means and standard deviation (error bar) from three experiments is depicted. ${ }^{*} \mathrm{P}<0.05$ vs. control.

$16 \mathrm{~h}$ later. The same pattern of change in $\mathrm{Cx} 43$ protein levels was observed after UVA-irradiation (Fig. 2B and C). After UVA-irradiation, $\mathrm{Cx} 43$ protein was significantly decreased. One hour after incubation, Cx43 protein gradually recovered and it returned to normal levels after $16 \mathrm{~h}$ incubation compared to unirradiated control cells. Thus, UVA reduces Cx43 expression at both the mRNA and protein levels, and this reduction is reversible at a UVA dose of $10 \mathrm{~J} / \mathrm{cm}^{2}$.

PKC activity in UVA-irradiated lens epithelial cells. UVA-irradiation stimulated PKC activity in SRA01/04 cells. PKC activity significantly increased within $4 \mathrm{~h}$ after UVA-irradiation compared to unexposed cells (Fig. 3). An increase $>58 \%$ in PKC activity was observed immediately after UVA-irradiation relative to control cells. After $1 \mathrm{~h}$ of incubation, a slight decrease of PKC activity was observed, but it remained significantly higher. Two hours later, the PKC 


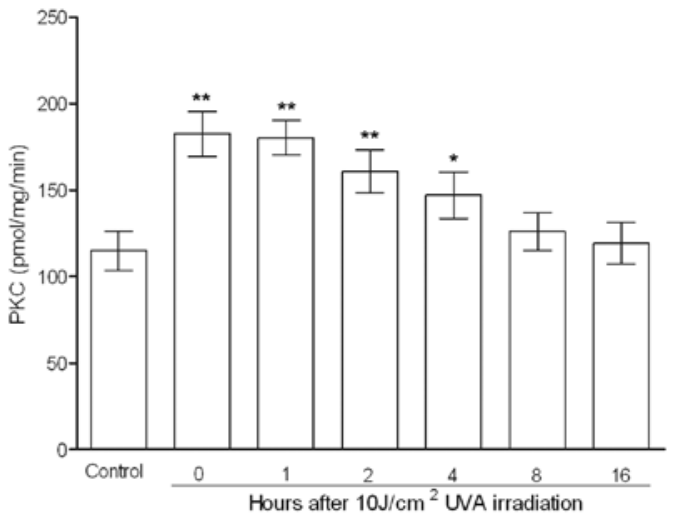

Figure 3. UVA-irradiation stimulated PKC activity in lens epithelial cells. SRA01/04 cells were exposed to $10 \mathrm{~J} / \mathrm{cm}^{2} \mathrm{UVA}$ and incubated up to $16 \mathrm{~h}$. PKC activity was measured by the PKC enzyme assay system. Compared to unirradiated control cells, PKC activity was significantly increased within $4 \mathrm{~h}$ after UVA-irradiation. Subsequently, PKC activity gradually decreased, and returned to normal levels by $16 \mathrm{~h}$ incubation. Data are the means $\pm \mathrm{SD}$ of results from triplicate experiments. ${ }^{*} \mathrm{P}<0.05,{ }^{* *} \mathrm{P}<0.01$ vs. control.

activity gradually decreased and was mostly recovered after $16 \mathrm{~h}$ of incubation, suggesting that UVA stimulated PKC activity is reversible.

UVA-irradiation generates ROS and stimulates lipid peroxidation. Flow cytometry analysis was performed to evaluate the ROS production by UVA-irradiation. UVA-irradiation generated a rapid and marked production of ROS (Fig. 4A), indicating the induction of oxidative stress by UVA. Following a $16 \mathrm{~h}$ incubation period, ROS levels decreased, suggesting that the balance of cellular stress was partially recovered (Fig. 4B). Similarly, lipid peroxidation measured by cellular MDA levels was rapidly increased after UVA-irradiation (Fig. 5). More than an 80\% increase of MDA was observed immediately after UVA-irradiation, and it remained 60 and $40 \%$ higher compared to control cells after 1 and $2 \mathrm{~h}$ of incubation, respectively. In agreement with ROS production, at $16 \mathrm{~h}$ after UVA-irradiation, there was a partial recovery of lipid peroxidation.

UVA-irradiation causes a decrease of GJIC activity. GJIC activity was assessed using an SLDT assay. SRA01/04 cells were exposed to $10 \mathrm{~J} / \mathrm{cm}^{2}$ of UVA, and scrape loaded to determine their capacity to transfer Lucifer yellow. As illustrated in Fig. 6, in control cells, the fluorescent dye was detected in five to six layers, and the Lucifer yellow-coupled cells were located on both sides of the scrape line, suggesting that control cells possess a high dye transfer capacity. In contrast, $2 \mathrm{~h}$ after UVA-irradiation, the fluorescent dye was detected in only one to two layers, and the Lucifer yellow-coupled cells were mostly located in the scrape line, reflecting that UVA-irradiation induced a decrease in the dye transfer capacity of SRA01/04 cells. However, the UVA-induced GJIC decrease was gradually recovered after $4 \mathrm{~h}$ of incubation and returned to normal levels by $16 \mathrm{~h}$ of incubation.

p38 activation in response to UVA-irradiation in lens epithelial cells. p38 is an important modulator of the adaptive cell response to environmental stress (24). To investigate whether
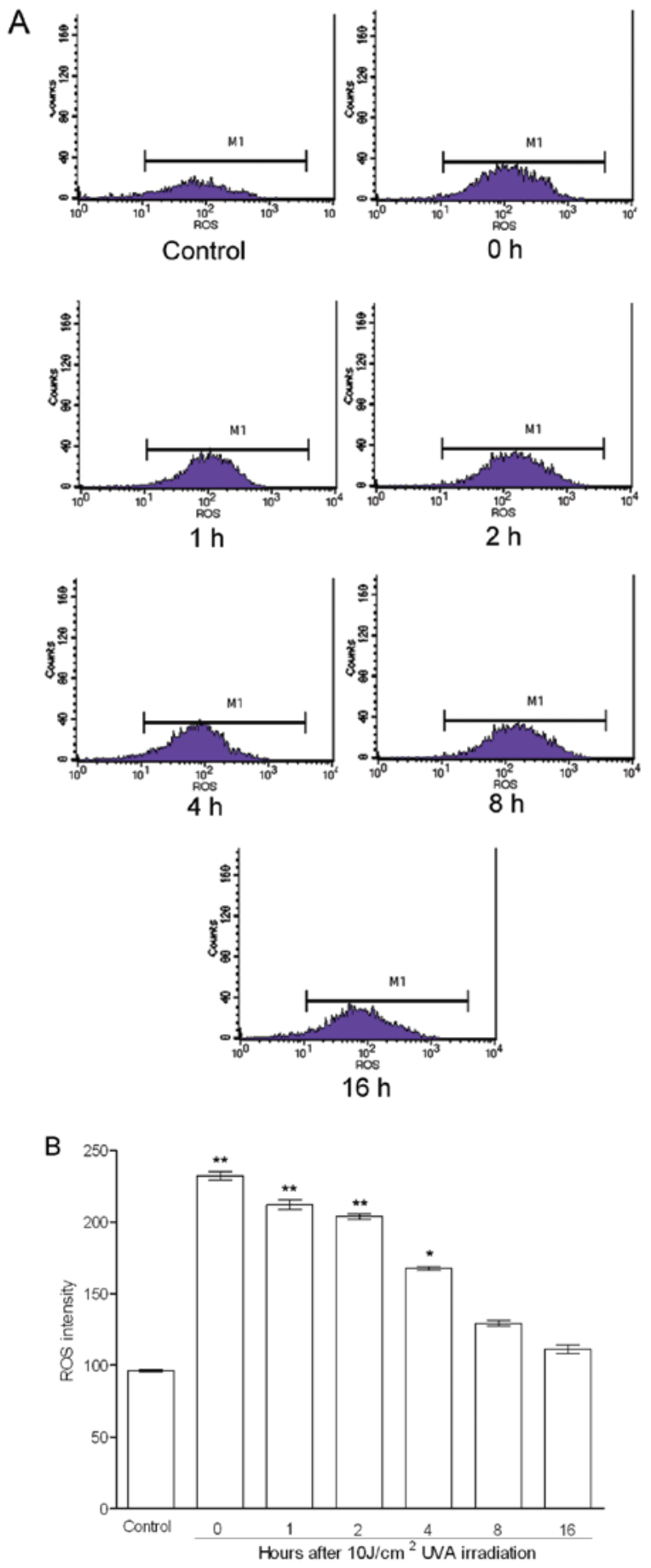

Figure 4. Generation of ROS after UVA-irradiation. After UVA-irradiation, SRA01/04 cells were incubated for up to $16 \mathrm{~h}$ for repair, and with the DCFH-DA probe for $20 \mathrm{~min}$. (A) ROS was measured by flow cytometry using the ROS detection kit. (B) Quantitative analysis of ROS generation. Compared to unirradiated control cells, UVA generated a rapid and marked production of ROS within $2 \mathrm{~h}$. After $4 \mathrm{~h}$ repair, the ROS level was decreased and return to normal after $16 \mathrm{~h}$ incubation. Data are the means $\pm \mathrm{SD}$ of results from triplicate experiments. ${ }^{*} \mathrm{P}<0.05,{ }^{* *} \mathrm{P}<0.01$ vs. control.

p38 activation was involved in UVA-irradiation, we exposed SRA01/04 cells with UVA at a dose of $10 \mathrm{~J} / \mathrm{cm}^{2}$, and incubated cells at $37^{\circ} \mathrm{C}$ for up to $16 \mathrm{~h}$. p38 activation was monitored by assessing the relative levels of $\mathrm{p} 38$ phosphorylation. The level of pho-p38 was increased within $2 \mathrm{~h}$ after UVA-irradiation, demonstrating that exposure to UVA in lens epithelial cells 


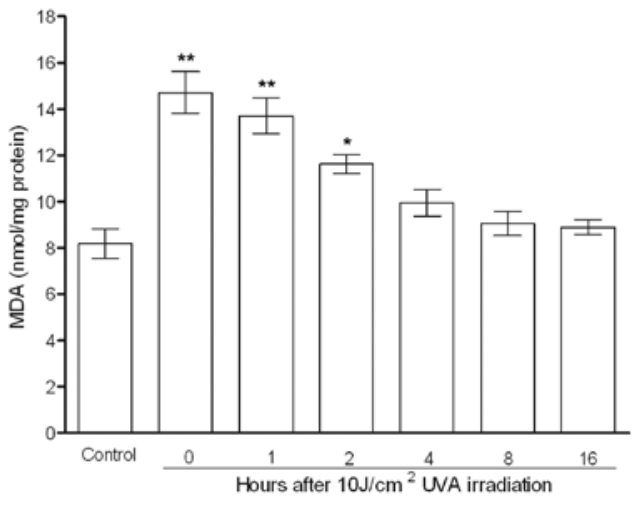

Figure 5. Lipid peroxidation after UVA-irradiation. SRA01/04 cells were plated in 60 -mm petri dishes. After UVA-irradiation, cells were incubated for up to $16 \mathrm{~h}$. Lipid peroxidation was analyzed by measuring the cellular MDA level using the MDA assay kit. More than $80 \%$ increase of MDA was observed immediately after UVA-irradiation, and it remained 60 and $40 \%$ higher, respectively compared to control cells after 1 and $2 \mathrm{~h}$ of incubation. After $16 \mathrm{~h}$, the cellular MDA returned to normal levels. Data are the means $\pm \mathrm{SD}$ of results from triplicate experiments. ${ }^{*} \mathrm{P}<0.05,{ }^{* *} \mathrm{P}<0.01$ vs. control.
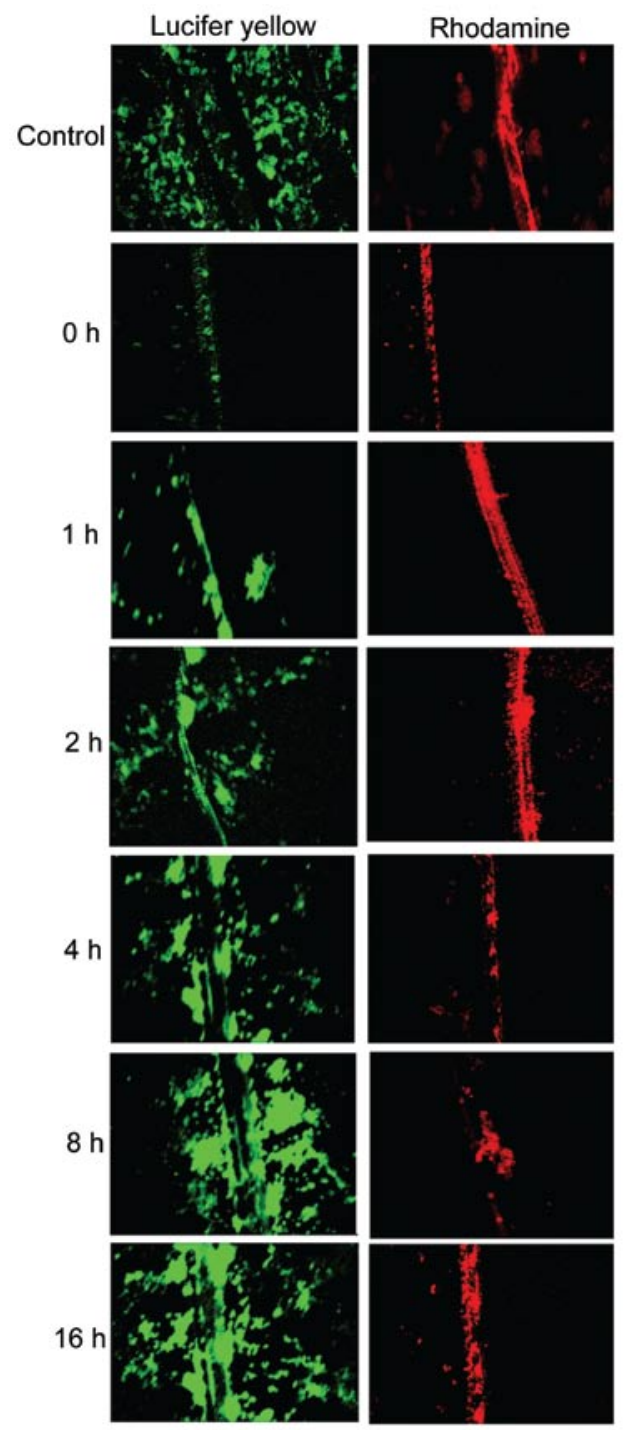

Figure 6. Gap junction intercellular communication activity in lens epithelial cells. Image analysis of SLDT assay. Cells were exposed to $10 \mathrm{~J} / \mathrm{cm}^{2}$ of UVA, and incubated for up to $16 \mathrm{~h}$. The scrape cells were stained with $0.05 \%$ Lucifer yellow fluorescent dye and $0.05 \%$ rhodamine-dextran. The dye-coupled cells were observed under a fluorescence microscope.

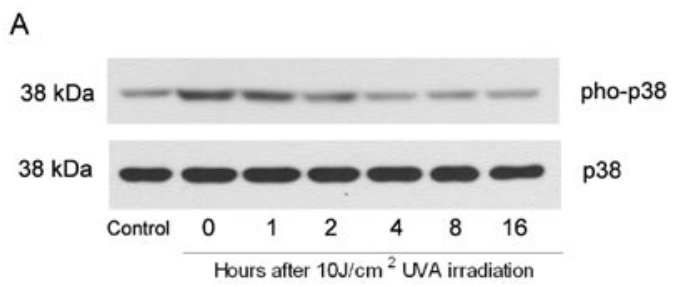

B

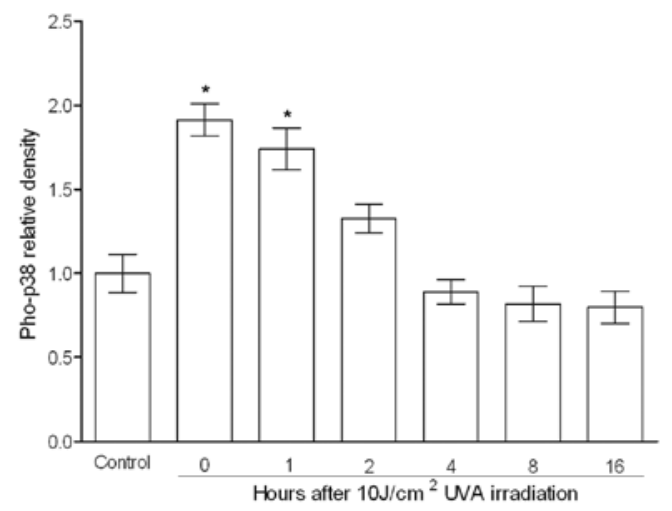

Figure 7. p38 activation in response to UVA. SRA01/04 cells were exposed to $10 \mathrm{~J} / \mathrm{cm}^{2}$ of UVA, and incubated for up to $16 \mathrm{~h}$, and harvested. (A) The cell lysates were subjected to Western blotting to monitor phosphorylation of p38. (B) The relative levels of phosphorylation of p38 were assessed by normalization to total p38. The level of pho-p38 was increased within $2 \mathrm{~h}$ after UVA-irradiation. Over $4 \mathrm{~h}$ incubation, p38 phosphorylation level was gradually decreased, and returned to the same level as compared to unirradiated control cells $16 \mathrm{~h}$ later. The means and standard deviation (error bar) from three experiments are depicted. ${ }^{*} \mathrm{P}<0.05$ vs. control.

resulted in p38 phosphorylation, as expected (Fig. 7). Notably, p38 phosphorylation level gradually decreased after $4 \mathrm{~h}$ incubation, and returned to the same level as compared to unirradiated control cells $16 \mathrm{~h}$ later, reflecting that the response to UVA stress in lens epithelial cells can be recovered (Fig. 7).

\section{Discussion}

Cataract is the most common pathology of the lens, and UVA-radiation is one of the important risk factor. Previous studies have shown that GJIC is a novel UVA target, and UVA-irradiation can disrupt the function of GJIC in human keratinocytes via p38 MAPK activation $(19,20)$. UVA can induce various pathological changes in the lens epithelium. However, it has not been reported that whether UVA can induce the alteration of connexin expression in the lens epithelium under physiological conditions and whether these damages are reversible. In this study, we found that UVA $(365 \mathrm{~nm})$ can disrupt GJIC in human lens epithelial cells. This disruption was reversible and due to alteration of $\mathrm{Cx} 43$ expression, generation of ROS and lipid peroxidation stimulation, which is dependent on p38 activation by UVA.

Connexin phosphorylation is a common event with important implication in a variety of cellular process including gating of gap junction (25). In the lens, PKC, MAPK and CKI and II can catalyze connexin phosphorylation. Many PKC activators can increase the variety of cell $\mathrm{Cx} 43$ phosphorylation and reduced gap junction function (18). PKC can also directly phosphorylate $\mathrm{Cx} 43$ and decrease the gap junction 
single-channel conductance and dye permeability in noncardiac cells of the dye (26). In our study, we found a decrease in Cx43 at both the mRNA and protein levels and an increase in PKC activity induced by UVA, suggesting that through PKC-activated Cx phosphrylation, UVA may promote the degradation of $\mathrm{Cx} 43$ and result in a decrease in intercellular communication. Gap junction has been reported as a new target of UVA-irradiation in the epidermis $(19,20)$. The gap junction can be regulated by $\mathrm{Cx} 43$ phosphorylation and dephosphorylation. Through this mechanism we demonstrated that lens epithelial cells exposed to UVA-irradiation display a reversible decrease in GJIC, supporting that $\mathrm{Cx} 43$ expression changes may be due to the regulation of the connexin phosphorylation status.

We observed that the reduction of GJIC activity was not due to a cytotoxic effect of UVA-irradiation, but rather due to ROS generation and lipid peroxidation in lens epithelial cells. We also demonstrated that this UVA-induced reduction was reversible at a dose of $10 \mathrm{~J} / \mathrm{cm}^{2}$. Our findings are consistent with previous studies (20). Inhibition of GJIC by UVA-irradiation has been reported to be associated with the deleterious effects of UVA on the human epidermis by generating ROS and compromising membrane stability (19). The role of ROS in GJIC is yet unclear, although it has been reported that oxidative stress can inhibit GJIC and antioxidants can reverse the down-regulation of GJIC $(19,27,28)$. Our findings suggest that UVA activates ROS generation and lipid peroxidation which induce connexin degradation and down-regulation of its expression is a major cause of gap junction disruption following UVA injury.

MAPKs including ERK1/2, BMK-1 (ERK5), p38, JNK can phosphorylate $\mathrm{Cx} 43$ on the Ser279 and Ser282 sites, which cause a rapid and transient decrease of GJIC (29). Different kinases can act on the same site, and the same kinase can also act on different sites. Many kinases and phosphatases can directly or indirectly phosphorylate $\mathrm{Cx} 43$ and affect the function of gap junction channels. In addition, various kinases and phosphatases can also interact and form a complicated regulatory network. The p38 MAPK signaling pathway allows cells to interpret a wide range of external signals and respond appropriately by generating a plethora of different biological effects (30). Phosphorylation and activation of p38 kinase is related to a cellular stress condition and its activity contributes to the regulation of growth arrest, differentiation and apoptosis in response to a variety of cellular stresses $(31,32)$. Previously, UVA-induced GJIC down-regulation in human keratinocytes has been reported to be involved in $\mathrm{p} 38$ activation-dependent $\mathrm{Cx} 43$ phosphorylation and degradation (19). In this study, we showed the phosphorylation of $\mathrm{p} 38$ after UVA-irradiation in lens epithelial cells, suggesting that UVA-induced p38 MAPK activation also plays an important role in modulation of GJIC in lens epithelial cells.

In conclusion, we found that UVA can disrupt the function of GJIC in lens epithelial cells. We demonstrated that this UVA-induced GJIC disruption is mediated by alteration of Cx43 expression, generation of ROS and lipid peroxidation stimulation, which is reversible and dependent on p38 activation. Future studies will focus on the experimental modulation of $\mathrm{Cx} 43$ expression and phosphorylation, and its effects on the signaling pathways in cataractogenesis.

\section{Acknowledgements}

This study was supported by grants from the National Natural Science Foundation of China (Grant nos. NSFC30872836 and NSFC30800651) and the Fund for Science and Technology Department of Liaoning Province (Grant no. 2009225011-3).

\section{References}

1. Balasubramanian D: Ultraviolet radiation and cataract. J Ocul Pharmacol Ther 16: 285-297, 2000.

2. Mukesh BN, Le A, Dimitrov PN, Ahmed S, Taylor HR and McCarty CA: Development of cataract and associated risk factors: the Visual Impairment Project. Arch Ophthalmol 124: 79-85, 2006.

3. West SK and Valmadrid CT: Epidemiology of risk factors for age-related cataract. Surv Ophthalmol 39: 323-334, 1995.

4. Li WC and Spector A: Lens epithelial cell apoptosis is an early event in the development of UVB-induced cataract. Free Radic Biol Med 20: 301-311, 1996.

5. Spector A, Kuszak JR, Ma W, Wang RR, Ho Y and Yang Y: The effect of photochemical stress upon the lenses of normal and glutathione peroxidase-1 knockout mice. Exp Eye Res 67: 457-471, 1998.

6. Spector A, Wang GM, Wang RR, Li WC and Kuszak JR: A brief photochemically induced oxidative insult causes irreversible lens damage and cataract. I. Transparency and epithelial cell layer. Exp Eye Res 60: 471-481, 1995.

7. De Maio A, Vega VL and Contreras JE: Gap junctions, homeostasis, and injury. J Cell Physiol 191: 269-282, 2002.

8. Alexander DB and Goldberg GS: Transfer of biologically important molecules between cells through gap junction channels. Curr Med Chem 10: 2045-2058, 2003.

9. Evans WH and Martin PE: Gap junctions: structure and function (Review). Mol Membr Biol 19: 121-136, 2002.

10. Boswell BA, VanSlyke JK and Musil LS: Regulation of lens gap junctions by transforming growth factor beta. Mol Biol Cell 21: 1686-1697, 2010.

11. Goodenough DA, Goliger JA and Paul DL: Connexins, connexons, and intercellular communication. Annu Rev Biochem 65: 475-502, 1996.

12. Yao J, Oite T and Kitamura M: Gap junctional intercellular communication in the juxtaglomerular apparatus. Am J Physiol Renal Physiol 296: F939-F946, 2009.

13. Kumar NM and Gilula NB: The gap junction communication channel. Cell 84: 381-388, 1996.

14. Eckert R, Adams B, Kistler J and Donaldson P: Quantitative determination of gap junctional permeability in the lens cortex. J Membr Biol 169: 91-102, 1999.

15. Baruch A, Greenbaum D, Levy ET, et al: Defining a link between gap junction communication, proteolysis, and cataract formation. J Biol Chem 276: 28999-29006, 2001.

16. Kistler J, Lin JS, Bond J, et al: Connexins in the lens: are they to blame in diabetic cataractogenesis? Novartis Found Symp 219: 97-112, 1999.

17. Krysko DV, Mussche S, Leybaert L and D'Herde K: Gap junctional communication and connexin43 expression in relation to apoptotic cell death and survival of granulosa cells. J Histochem Cytochem 52: 1199-1207, 2004.

18. Girao H and Pereira P: Phosphorylation of connexin 43 acts as a stimuli for proteasome-dependent degradation of the protein in lens epithelial cells. Mol Vis 9: 24-30, 2003.

19. Bellei B, Mastrofrancesco A, Briganti S, et al: Ultraviolet A induced modulation of gap junctional intercellular communication by P38 MAPK activation in human keratinocytes. Exp Dermatol 17: 115-124, 2008.

20. Provost N, Moreau M, Leturque A and Nizard C: Ultraviolet A radiation transiently disrupts gap junctional communication in human keratinocytes. Am J Physiol Cell Physiol 284: C51-C59, 2003.

21. Livak KJ and Schmittgen TD: Analysis of relative gene expression data using real-time quantitative PCR and the 2(-Delta Delta C(T)) method. Methods 25: 402-408, 2001.

22. Li AF and Roy S: High glucose-induced down-regulation of connexin 43 expression promotes apoptosis in microvascular endothelial cells. Invest Ophthalmol Vis Sci 50: 1400-1407, 2009. 
23. Sato T, Haimovici R, Kao R, Li AF and Roy S: Down-regulation of connexin 43 expression by high glucose reduces gap junction activity in microvascular endothelial cells. Diabetes 51: 1565-1571, 2002.

24. Kyriakis JM and Avruch J: Mammalian mitogen-activated protein kinase signal transduction pathways activated by stress and inflammation. Physiol Rev 81: 807-869, 2001.

25. Lampe PD and Lau AF: Regulation of gap junctions by phosphorylation of connexins. Arch Biochem Biophys 384: 205-215, 2000 .

26. Lin D, Boyle DL and Takemoto DJ: IGF-I-induced phosphorylation of connexin 43 by PKCgamma: regulation of gap junctions in rabbit lens epithelial cells. Invest Ophthalmol Vis Sci 44 $1160-1168,2003$

27. Ruch RJ and Klaunig JE: Inhibition of mouse hepatocyte intercellular communication by paraquat-generated oxygen free radicals. Toxicol Appl Pharmacol 94: 427-436, 1988.
28. Hu J, Speisky H and Cotgreave IA: The inhibitory effects of boldine, glaucine, and probucol on TPA-induced down regulation of gap junction function. Relationships to intracellular peroxides, protein kinase $\mathrm{C}$ translocation, and connexin 43 phosphorylation. Biochem Pharmacol 50: 1635-1643, 1995.

29. Warn-Cramer BJ, Lampe PD, Kurata WE, et al: Characterization of the mitogen-activated protein kinase phosphorylation sites on the connexin-43 gap junction protein. J Biol Chem 271: 3779-3786, 1996.

30. Cuadrado A and Nebreda AR: Mechanisms and functions of $\mathrm{p} 38$ MAPK signalling. Biochem J 429: 403-417, 2010.

31. Kim AL, Zhu Y, Zhu H, et al: Resveratrol inhibits proliferation of human epidermoid carcinoma A431 cells by modulating MEK1 and AP-1 signalling pathways. Exp Dermatol 15: 538-546, 2006.

32. Harper SJ and LoGrasso P: Signalling for survival and death in neurones: the role of stress-activated kinases, JNK and p38. Cell Signal 13: 299-310, 2001. 